\title{
The University of Kansas Cancer Center
}

National Cancer Institute

\section{Source}

National Cancer Institute. The University of Kansas Cancer Center. NCI Thesaurus. Code C105627.

The University of Kansas Cancer Center is focused on using drug discovery, delivery, and development to transform the delivery of clinical care in Kansas and Missouri. It became an NCl-designated cancer center in 2012. Its partners include University of Kansas, University of Kansas Medical Center, University of Kansas Hospital, KU School of Pharmacy, University of Kansas School of Medicine, Wichita, and Stowers Institute for Medical Research. 